\title{
Determinants of Water Connection Type and Ownership of Water-Using Appliances in Ireland
}

\author{
Sean Lyons • Joe O’Doherty • Richard S. J. Tol
}

Received: 23 October 2007 / Accepted: 8 January 2010 /

Published online: 15 April 2010

(C) The Author(s) 2010. This article is published with open access at Springerlink.com

\begin{abstract}
Developing optimal policies on management of water resources, investment in relevant infrastructure and the protection of the environment requires data on the current and likely future demand for water services. In jurisdictions without water metering, information on the factors influencing demand tends to be limited. Microdata from household surveys can provide some relevant information. Domestic water demand is influenced both by the number of households and their characteristics, in particular the extent to which they employ water-using appliances. This paper focuses on domestic ownership of water-using appliances in the Republic of Ireland, a country where rapid economic and demographic change have put pressure on water and sewerage infrastructure but where there is little domestic metering. Using a large household micro-dataset, we use regression analysis to examine the determinants of the water and sewage mains connection status of Irish homes and to identify the characteristics of households that are associated with having larger or smaller numbers of appliances. Our empirical results suggest that Ireland will have a rising share of mains water and sewerage connections in the future. Household income, house price, dwelling types other than 'detached', younger dwellings, and urban location are all positively associated with having a mains connection. The number of types of water-using appliance in a household is positively associated with income, house price, number of residents, owner-occupation, having children (or, to a lesser extent, multiple people) in the household, having a detached house, being located in a rural area and living in a dwelling built after 1997.
\end{abstract}

S. Lyons $(\varangle) \cdot$ J. O’Doherty · R. S. J. Tol

Economic and Social Research Institute, Whitaker Square,

Sir John Rogerson's Quay, Dublin 2, Ireland

e-mail: sean.lyons@esri.ie

R. S. J. Tol

Institute for Environmental Studies, Vrije Universiteit, Amsterdam, The Netherlands

R. S. J. Tol

Department of Spatial Economics, Vrije Universiteit, Amsterdam, The Netherlands 
Keywords Water usage Ireland $\cdot$ Appliance ownership $\cdot$ Econometric modelling

\title{
Abbreviation
}

\author{
NSHQ National Survey of Housing Quality
}

\section{Introduction}

Efficient supply of drinking water and sewerage services over time requires predictions of likely future demand, together with the societal costs and benefits of each option for supplying these services. Optimal investment in water infrastructure and measures to protect the environment also require information about the factors influencing demand for water. Jurisdictions that employ metering and per-unit charging for water use have an advantage in obtaining the relevant data, since it is possible to observe directly how demand varies over time for different types of users. Per unit charging can also facilitate efficient management of water scarcity, by allowing the marginal costs of supply to be related to the marginal benefits. This is recognised by policymakers; for example, extending the coverage of metering and efficient pricing of water services is an important goal of European water policy (European Commission 2007).

However, not all jurisdictions charge for water or meter the quantities supplied to specific end users, especially households. In this paper, we develop and apply an approach for approximating one important driver of household demand in jurisdictions without water metering: the prevalence of domestic appliances that use water. This type of analysis is not a substitute for metering, but it provides policyrelevant information that cannot be gleaned from aggregate data alone.

In the absence of domestic metering, household water usage is unlikely to be directly observable, but it may still be possible to draw useful inferences about the likely pattern of water use from household characteristics. This paper focuses on domestic ownership of water-using appliances in the Republic of Ireland, a country where rapid economic and demographic change are putting pressure on water and sewerage infrastructure, but where domestic water use is not generally metered or priced. Although the government has announced plans to introduce domestic water metering and charging in Ireland (Lenihan 2009), this will take time. At present, publicly available information on domestic usage of water in Ireland is very limited (Tol et al. 2009). Using a large household micro-dataset, we examine the determinants of the water and sewage mains connection status of Irish homes and identify the characteristics of households that are associated with having larger or smaller numbers of appliances.

Determinants of residential water use have been studied in many parts of the world, including Phoenix (Wentz and Gober 2007); Melbourne (Aitken et al. 1991); Masvingo (Dube and van der Zwaag 2003); Honolulu (Malla and Gopalakrishnan 1997); Bangkok (Babel et al. 2003) and Adelaide (Troy and Holloway 2004; Dandy et al. 1997). A survey of tools for residential water conservation by Inman and Jeffrey (2006) cites studies from additional countries. These studies generally concur on many of the factors that affect domestic demand for water, namely the existence and scale of water charges; house size; income; number of inhabitants; the number, 
type and frequency of use of water-using appliances; age of household members; the presence of a swimming pool and large gardens; and in one study at least, the usage patterns of one's neighbours (see Aitken et al. 1991). Inman and Jeffrey (2006) also point out that the presence of metering may have an effect on water use independent of the charging method applied.

In general, larger, more affluent households with children tend to use more water, although the presence of a swimming pool and large watered garden can outweigh other factors (Wentz and Gober 2007).

Analyses of the determinants of water and sewage mains connectivity are rare. Tunis, (McPhail 1994), Cairo (Hoehn and Krieger 2000) and Halle (Haug 2004) have been the subjects of studies aiming to understand the costs, benefits and efficiencies of mains connectivity and improvements made to this utility. In the process of determining this, the authors of these studies found that location, population density and household characteristics (e.g. income, number of persons in the household, housing tenure) could have an impact on the quality, if not the existence, of a mains connection. To our knowledge, no similar analyses have been conducted in Ireland.

Unlike the locations for the above analyses, water is (currently) free for domestic households in Ireland. Scott $(1999,2)$ notes of this that 'as for most goods or services treated in this manner, the predictable outcome is under-funding, over-use of the resource, disincentives to the use of efficient technology, losses of water in distribution systems, and environmental degradation'. Scott has written extensively in relation to the lack of domestic water metering and pricing in Ireland, and policy changes that could be made to counteract the associated negative effects of this situation (see Scott 1999; Scott and Lawlor 1994, 1997; Scott and Morgenroth 2006; Lawlor et al. 2007). In another study, Camp, Dresser and McKee (2004) estimate total water demand by sector and county in Ireland, but do not analyse the drivers of differences in water use. To our knowledge, these remain the only published analyses of the determinants of residential water demand in Ireland.

The most comprehensive effort to investigate the relationships between household and dwelling characteristics in Ireland is the National Survey of Housing Quality, 2001-2002 (NSHQ; Watson and Williams 2003). The survey 'obtained detailed information from a representative sample of over 40,000 householders on characteristics and problems of the dwelling, and on the household members' (ibid, v). As such, it provides a snapshot of a household's appliances and mains connectivity status. Watson and Williams (2003) provide descriptive statistics, but do not subject the data to econometric analysis. In this paper we use cross-sectional econometric models analyse the data from the NSHQ. Since the NSHQ has so far been a onceoff survey, commissioned by the Department of the Environment, Heritage and Local Government (DEHLG) and conducted by the Economic and Social Research Institute, it was not possible to conduct any longitudinal or time-series analysis using the data.

By conducting regression analysis on the data behind the NSHQ, it is possible to determine what factors are likely to influence the mains connectivity and appliance ownership status of households in Ireland.

The remainder of this paper will proceed as follows. The next section outlines the econometric models being analysed. Section 3 describes the NSHQ data and Section 4 presents the results from the models. Finally, the concluding section summarises our results and draws inferences for policy. 


\section{Methods}

Our first model examines the determinants of whether a household has a mains water or sewerage connection. Having such a connection is a discrete state rather than a continuous variable, so in line with established econometric practice we model the probability of each possible state (either 'house has a mains connection' or 'house has no mains connection') as a function of a vector of household characteristics. For example, the probability of having a mains water connection $W$ is modelled as a function of vector $\mathbf{X}$ and a logistically distributed random error term $\varepsilon$. Thus we estimate $\operatorname{Pr}(W)=f(\mathbf{X}, \varepsilon)$ using logistic ("logit") regression. See Wooldridge (2002) for more details of the logit model and other discrete response models such as the ordered logit model, mentioned below.

In order to analyse the relationship between household characteristics and the number of different types of appliances to which each household has access, an ordered logit model was used. The set of appliances possessed by a household falls into a range of discrete values with a lower bound of zero. The values have a natural ordering: from fewer to more. Ordered logit models estimate the associations between an ordinal dependent variable and a vector of independent variables. The method involves estimating a score for each observation that is a function of the independent variables and a simultaneously estimated set of "cut-points". The probability that the estimated score for an observation, plus a random error, is within the range of specified cut-points for a given place in the ordering indicates the probability that this observation gave rise to the relevant outcome. In ordered logit, the random error is assumed to be logistically distributed.

Discrete choice models have previously been used to study the determinants of water demand, use and supply. For example, Larson and Gnedenko (1999) conducted an analysis of methods used by residents of Moscow in order to avoid waterborne diseases. The authors used a discrete dependent variable from survey data in order 'to investigate how choices of avoidance measure (i.e. methods of avoiding the public mains such as bottled or filtered water) are related to respondents' opinions of their water quality and service and other socioeconomic characteristics'. Elsewhere, Vossler et al. (1998) use a similar model to look at the decision of households to accept or reject water metering over flat-rate charges.

The next section describes the NSHQ data employed in this analysis.

\section{Data}

The Economic and Social Research Institute, Dublin was commissioned by the Irish Department of Environment, Heritage and Local Government (DEHLG) to carry out the Irish National Survey of Housing Quality (NSHQ) in 2001-2002. The survey gathered information from a sample of over 40,000 householders on characteristics and problems of the dwelling, and on household members. The resultant micro data were made available to the authors of this paper for the purpose of studying patterns of water supply and demand.

With regard to connectivity, the NSHQ asked respondents about their sewage and water supply; specifically, what type of system they were connected to. In both instances, connection to the public mains was the most common response. A binary 
Table 1 Independent variables for regression analysis (reference categories in italics)

\begin{tabular}{|c|c|}
\hline Variable & Description \\
\hline Sewagetype & Whether a dwelling has a mains sewage connection \\
\hline watertype & Whether a dwelling has a mains water connection \\
\hline yrshere & The number of years a household has been resident at the dwelling \\
\hline hvalue & Estimate of the dwelling's value (in IR£; IR£1 = €1.27) \\
\hline HHincome & $\begin{array}{l}\text { Declared income of the household, midpoint of selected range } \\
\text { (IR£ per week) }\end{array}$ \\
\hline HHsize & Number of persons in the household \\
\hline age $<40$ & Dummy: householder is less than 40 years old \\
\hline age40_64 & Dummy: householder is between 40 and 64 years old, inclusive \\
\hline age65plus & Dummy: householder is over 65 years old, inclusive \\
\hline locDublin & Dummy: location is in the Dublin region \\
\hline locBMWurban & $\begin{array}{l}\text { Dummy: location is in an urban part of the border-midlands-west } \\
\text { ("BMW") region }\end{array}$ \\
\hline locothurban & Dummy: location is urban but not in Dublin or BMW \\
\hline locruralBMW & Dummy: location is rural and in BMW \\
\hline locothrural & Dummy: location is rural but not in Dublin or BMW \\
\hline tenureOwn & Dummy: home is owned outright \\
\hline tenurePurch & Dummy: home is being purchased (i.e. mortgage) \\
\hline tenureLocalA & Dummy: home is rented from a local authority \\
\hline tenurePrRent & Dummy: home is rented from a private landlord \\
\hline tenureVolOrg & Dummy: home is rented from a voluntary organisation \\
\hline tenureRentFr & Dummy: home is lived in rent-free \\
\hline socProf & Dummy: social status is 'professional' \\
\hline socLowProf & Dummy: social status is 'low professional' \\
\hline socOthNonMan & Dummy: social status is 'other non-manual' \\
\hline socSkill & Dummy: social status is 'skilled' \\
\hline socSemiSkill & Dummy: social status is 'semi-skilled' \\
\hline socUnskill & Dummy: social status is 'unskilled' \\
\hline socUnknown & Dummy: social status is 'unknown' \\
\hline dwellDetached & Dummy: dwelling is a detached house \\
\hline dwellSemiD & Dummy: dwelling is a semi-detached house \\
\hline dwellTerrace & Dummy: dwelling is a terraced house \\
\hline dwellPurpApt & Dummy: dwelling is a purpose-built apartment \\
\hline dwellHousApt & Dummy: dwelling is an apartment in a converted house \\
\hline dwellCaravan & Dummy: dwelling is a caravan \\
\hline HAgePre1900 & Dummy: dwelling was originally built before 1900 \\
\hline HAge1900_40 & Dummy: dwelling was originally built between 1900 and 1940 \\
\hline HAge1941_60 & Dummy: dwelling was originally built between 1941 and 1960 \\
\hline HAge1961_70 & Dummy: dwelling was originally built between 1961 and 1970 \\
\hline HAge1971_80 & Dummy: dwelling was originally built between 1971 and 1980 \\
\hline HAge1981_90 & Dummy: dwelling was originally built between 1981 and 1990 \\
\hline HAge1991_96 & Dummy: dwelling was originally built between 1991 and 1996 \\
\hline HAgeAfter97 & Dummy: dwelling was originally built between after 1997 \\
\hline HH1under65 & Dummy: household consists of 1 person aged less than 65 \\
\hline HH1over65 & Dummy: household consists of 1 person, aged 65 or older \\
\hline HHCoupleKids & Dummy: household consists of a couple with child(ren) \\
\hline HHOthKids & $\begin{array}{l}\text { Dummy: household consists of adult(s) (not a couple) with } \\
\text { child(ren) }\end{array}$ \\
\hline HHParAduKids & Dummy: household consists of parents living with adult child(ren) \\
\hline HHOthAdUn65 & Dummy: household consists of adults, all under 65 \\
\hline HHOthAdOv65 & Dummy: household consists of adults only, all over 65 \\
\hline
\end{tabular}


variable was created for both sewage and water taking a value of 1 for 'public mains connection' and 0 for all other options. In the case of sewage connections, respondents were asked which system they were connected to, the options being 'public mains sewer', 'private septic tank/other private system', 'group scheme (septic

Table 2 Descriptive statistics for variables used in regressions

\begin{tabular}{|c|c|c|c|c|}
\hline \multirow[t]{2}{*}{ Variable } & \multicolumn{2}{|c|}{ Mains sewage and water } & \multicolumn{2}{|c|}{ Number of appliances } \\
\hline & Mean & Std. Dev. & Mean & Std. Dev. \\
\hline sewagetype & 0.579 & 0.494 & 0.579 & 0.494 \\
\hline watertype & 0.743 & 0.437 & 0.743 & 0.437 \\
\hline totwateruse & & & 1.86 & 0.732 \\
\hline yrshere & 23.3 & 17.5 & 23.3 & 17.5 \\
\hline hvalue & 145,000 & 117,000 & 145,000 & 117,000 \\
\hline HHincome & 547 & 340 & 547 & 340 \\
\hline HHsize & 3.44 & 1.71 & 3.44 & 1.71 \\
\hline age40_64 & 0.557 & 0.497 & 0.558 & 0.497 \\
\hline age65plus & 0.285 & 0.451 & 0.285 & 0.451 \\
\hline locBMWurban & 0.0918 & 0.289 & 0.0915 & 0.288 \\
\hline locothurban & 0.196 & 0.397 & 0.196 & 0.397 \\
\hline locruralBMW & 0.301 & 0.459 & 0.301 & 0.459 \\
\hline locothrural & 0.245 & 0.43 & 0.245 & 0.43 \\
\hline tenurePurch & 0.353 & 0.478 & 0.353 & 0.478 \\
\hline tenureLocalA & 0.0505 & 0.219 & 0.0505 & 0.219 \\
\hline tenurePrRent & 0.0283 & 0.166 & 0.0282 & 0.166 \\
\hline tenureVolOrg & 0.00146 & 0.0382 & 0.00147 & 0.0383 \\
\hline tenureRentFr & 0.00582 & 0.0761 & 0.00584 & 0.0762 \\
\hline socLowProf & 0.168 & 0.374 & 0.168 & 0.374 \\
\hline socOthNonMan & 0.171 & 0.377 & 0.171 & 0.377 \\
\hline socSkill & 0.168 & 0.374 & 0.168 & 0.374 \\
\hline socSemiSkill & 0.107 & 0.31 & 0.107 & 0.31 \\
\hline socUnskill & 0.0872 & 0.282 & 0.0872 & 0.282 \\
\hline socUnknown & 0.195 & 0.396 & 0.195 & 0.396 \\
\hline dwellSemiD & 0.239 & 0.427 & 0.239 & 0.427 \\
\hline dwellTerrace & 0.19 & 0.392 & 0.19 & 0.392 \\
\hline dwellPurpApt & 0.00658 & 0.0809 & 0.00658 & 0.0808 \\
\hline dwellHousApt & 0.00318 & 0.0563 & 0.00319 & 0.0564 \\
\hline dwellCaravan & 0.00205 & 0.0453 & 0.00203 & 0.045 \\
\hline HAge1900_40 & 0.12 & 0.325 & 0.12 & 0.325 \\
\hline HAge1941_60 & 0.128 & 0.334 & 0.128 & 0.334 \\
\hline HAge1961_70 & 0.117 & 0.321 & 0.117 & 0.321 \\
\hline HAge1971_80 & 0.237 & 0.425 & 0.237 & 0.425 \\
\hline HAge1981_90 & 0.15 & 0.357 & 0.15 & 0.357 \\
\hline HAge1991_96 & 0.075 & 0.263 & 0.075 & 0.263 \\
\hline HAgeAfter97 & 0.0605 & 0.238 & 0.0604 & 0.238 \\
\hline HH1over65 & 0.0603 & 0.238 & 0.0602 & 0.238 \\
\hline HHCoupleKids & 0.361 & 0.48 & 0.361 & 0.48 \\
\hline HHOthKids & 0.0399 & 0.196 & 0.04 & 0.196 \\
\hline HHParAduKids & 0.267 & 0.443 & 0.267 & 0.443 \\
\hline HHOthAdUn65 & 0.131 & 0.337 & 0.131 & 0.337 \\
\hline HHOthAdOv65 & 0.0939 & 0.292 & 0.0938 & 0.292 \\
\hline
\end{tabular}


tank or other)', 'piped disposal (no treatment)', 'none' or 'don't know'. For water supply, respondents were asked which system they were connected to, the options being 'public mains', 'well', 'group scheme', 'rainwater tank', 'other source' or 'none'.

With regard to appliance ownership, the NSHQ does not include data on total water usage by households - as noted earlier, domestic usage is not normally metered in Ireland-but it does contain information on the presence or absence of certain water-using appliances in each household. In particular, it asks about the presence of dishwashers, washing machines/washer-dryers, the presence of a bath (but no shower), and power-showers in the home. The two latter questions are of course mutually exclusive. The NSHQ also asks about the presence of sinks, wash-hand basins and toilets, but these appliances were present in nearly every home so we have omitted them from the analysis. After these exclusions, the maximum number of different types of appliances that any one household can have is three (i.e. there are four categories, as a household can also have none of the specified appliances). Note that our data only capture presence of certain appliances, not the intensity of use.

The dependent variables described above were included in regressions with the explanatory variables detailed in Tables 1 and 2. Unfortunately, there were only a limited number of observations for the total floor space of the dwelling and for the length of ownership by the household currently living in the dwelling, so these variables were omitted from this analysis. Encouraging more respondents to provide floor space data would be helpful in future surveys of this kind. However, by far the most useful additional data would be metered water usage. Including this information would allow a much more direct analysis of the relationships between household characteristics and water usage. In the Irish case, we hope that such information will become available as metering is rolled out in the future.

\section{Results}

This section presents the results of the three regressions run on the NSHQ data, a logit model for the mains connectivity status of a dwelling and an ordered logit for the total number of appliances present in a dwelling. When a result is presented as a percentage it indicates the change in the odds of a unit change in the dependent variable. All data analysis and regressions reported in this paper were performed in Stata version 10 SE.

\subsection{Mains Connectivity}

As explained in the last section, logit regressions were run against the variables detailed in Table 1, with outcomes being dichotomous, either 'mains connection' or 'no mains connection'. Table 3 shows the results of these regressions. Below we outline the main results from these models.

Location Rural dwellings are much less likely to have mains connections than urban ones, though the differences between Dublin and other urban areas are not always significant. The probability of a home in a rural location having a mains sewage (water) connection is around 95\% (90\%) lower than one in Dublin. 
Table 3 Regression on sewage and water system in home using a logit estimator, DV $=1$ if mains, 0 if not mains

\begin{tabular}{|c|c|c|c|c|}
\hline \multirow[t]{2}{*}{ Variable } & \multicolumn{2}{|c|}{ Sewage system } & \multicolumn{2}{|c|}{ Water supply } \\
\hline & Odds ratio & Std. error & Odds ratio & Std. error \\
\hline yrshere & 0.981 & $0.00163^{\mathrm{a}}$ & 0.992 & $0.00115^{\mathrm{a}}$ \\
\hline Inhvalue & 1.29 & $0.0465^{\mathrm{a}}$ & 1.24 & $0.0355^{\mathrm{a}}$ \\
\hline InHHincome & 1.20 & $0.0478^{\mathrm{a}}$ & 1.05 & $0.0323^{\mathrm{c}}$ \\
\hline HHsize & 0.925 & $0.0171^{\mathrm{a}}$ & 0.952 & $0.0132^{\mathrm{a}}$ \\
\hline age $<40$ & REF & & REF & \\
\hline age $40 \_64$ & 1.05 & 0.0687 & 1.17 & $0.0631^{\mathrm{a}}$ \\
\hline age65plus & 0.980 & 0.0914 & 1.09 & 0.0793 \\
\hline locDublin & REF & & REF & \\
\hline locBMWurban & 1.21 & 0.146 & 1.02 & 0.153 \\
\hline locothurban & 1.54 & $0.173^{\mathrm{a}}$ & 1.70 & $0.248^{\mathrm{a}}$ \\
\hline locruralBMW & 0.0389 & $0.0037^{\mathrm{a}}$ & 0.0831 & $0.00922^{\mathrm{a}}$ \\
\hline locothrural & 0.0502 & $0.00472^{\mathrm{a}}$ & 0.0977 & $0.0108^{\mathrm{a}}$ \\
\hline tenureOwn & REF & & REF & \\
\hline tenurePurch & 1.12 & $0.0548^{\mathrm{b}}$ & 1.11 & $0.0437^{\mathrm{a}}$ \\
\hline tenureLocalA & 2.08 & $0.265^{\mathrm{a}}$ & 1.59 & $0.182^{\mathrm{a}}$ \\
\hline tenurePrRent & 2.41 & $0.409^{\mathrm{a}}$ & 1.93 & $0.317^{\mathrm{a}}$ \\
\hline tenureVolOrg & 31.2 & $34.0^{\mathrm{a}}$ & 7.81 & $8.18^{\mathrm{b}}$ \\
\hline tenureRentFr & 1.11 & 0.253 & 0.957 & 0.181 \\
\hline socProf & REF & & REF & \\
\hline socLowProf & 0.937 & 0.0697 & 0.873 & $0.0571^{\mathrm{b}}$ \\
\hline socOthNonMan & 0.670 & $0.0524^{\mathrm{a}}$ & 0.683 & $0.0449^{\mathrm{a}}$ \\
\hline socSkill & 0.755 & $0.0595^{\mathrm{a}}$ & 0.818 & $0.0548^{\mathrm{a}}$ \\
\hline socSemiSkill & 0.910 & 0.080 & 0.847 & $0.0631^{\mathrm{b}}$ \\
\hline socUnskill & 0.88 & 0.084 & 0.902 & 0.0715 \\
\hline socUnknown & 0.833 & $0.067^{\mathrm{b}}$ & 0.780 & $0.0533^{\mathrm{a}}$ \\
\hline dwellDetached & REF & & REF & \\
\hline dwellSemiD & 26.8 & $1.67^{\mathrm{a}}$ & 7.56 & $0.509^{\mathrm{a}}$ \\
\hline dwellTerrace & 81.6 & $7.97^{\mathrm{a}}$ & 16.8 & $1.71^{\mathrm{a}}$ \\
\hline dwellPurpApt & 15.4 & $6.48^{\mathrm{a}}$ & 4.44 & $1.80^{\mathrm{a}}$ \\
\hline dwellHousApt & 22.6 & $8.85^{\mathrm{a}}$ & 5.77 & $2.4^{\mathrm{a}}$ \\
\hline dwellCaravan & 2.06 & $0.712^{\mathrm{b}}$ & 1.79 & $0.55^{\mathrm{c}}$ \\
\hline HAgePre1900 & REF & & REF & \\
\hline HAge1900_40 & 1.30 & $0.109^{\mathrm{a}}$ & 1.21 & $0.0681^{\mathrm{a}}$ \\
\hline HAge1941_60 & 1.55 & $0.134^{\mathrm{a}}$ & 1.38 & $0.0856^{\mathrm{a}}$ \\
\hline HAge1961_70 & 1.96 & $0.171^{\mathrm{a}}$ & 1.64 & $0.109^{\mathrm{a}}$ \\
\hline HAge1971_80 & 1.70 & $0.127^{\mathrm{a}}$ & 1.54 & $0.0831^{\mathrm{a}}$ \\
\hline HAge1981_90 & 1.30 & $0.108^{\mathrm{a}}$ & 1.25 & $0.076^{\mathrm{a}}$ \\
\hline HAge1991_96 & 1.42 & $0.142^{\mathrm{a}}$ & 1.35 & $0.106^{\mathrm{a}}$ \\
\hline HAgeAfter97 & 1.40 & $0.146^{\mathrm{a}}$ & 1.22 & $0.0997^{\mathrm{b}}$ \\
\hline HH1under65 & REF & & REF & \\
\hline HH1over65 & 1.60 & $0.226^{\mathrm{a}}$ & 1.03 & 0.110 \\
\hline
\end{tabular}

Number of persons in the household We find a significant inverse relationship between the number of persons in a household and the odds of having a mains connection. For each additional person, the probability of mains service falls by $7 \%$ for sewerage and $5 \%$ for water supply. There is likely to be a complex relationship between this variable and the size, location and type of residence. 
Table 3 (continued)

\begin{tabular}{|c|c|c|c|c|}
\hline \multirow[t]{2}{*}{ Variable } & \multicolumn{2}{|c|}{ Sewage system } & \multicolumn{2}{|c|}{ Water supply } \\
\hline & Odds ratio & Std. error & Odds ratio & Std. error \\
\hline HHCoupleKids & 0.876 & 0.110 & 0.853 & 0.0834 \\
\hline HHOthKids & 1.02 & 0.161 & 0.960 & 0.123 \\
\hline HHParAduKids & 0.997 & 0.117 & 0.906 & 0.0827 \\
\hline HHOthAdUn65 & 0.940 & 0.107 & 0.903 & 0.081 \\
\hline HHOthAdOv65 & 1.51 & $0.202^{\mathrm{a}}$ & 1.16 & 0.119 \\
\hline Number of obs. & 35,551 & & 35,551 & \\
\hline LR $\chi^{2}(38)$ & $30,100[0.00]$ & & 14,200 & \\
\hline Log likelihood & $-9,170$ & & $-13,200$ & \\
\hline Pseudo $R^{2}$ & 0.621 & & 0.350 & \\
\hline
\end{tabular}

$R E F$ reference category

a Significant at the $1 \%$ level

${ }^{\mathrm{b}}$ Significant at the $5 \%$ level

' Significant at the $10 \%$ level

House value The more expensive a dwelling is, the more likely it is to have mains connections. A doubling in the value of a residence increases the odds of either a sewage or water mains connection by a factor of $20-30 \%$ (or vice versa: it may well be that the presence of mains connections increase the house value).

Household income Household income is positively correlated with house value (correlation $=0.33),{ }^{1}$ so it is not surprising that a higher income also means that a dwelling is more likely to have a sewage mains connection (a 10\% rise in weekly household income increases the odds of having a mains sewage connection by $2 \%$ ). However, for water mains the association is weaker and only marginally significant.

Tenure type The baseline scenario for this category is 'own outright', and all other types are more likely to have mains connections (though 'rent free' is not significant), particularly those renting in the private sector.

Dwelling type The baseline scenario for this category is 'detached' and all other categories are more likely to have mains connections. Terraced houses are the most likely to have mains connections (the odds of having a mains connection are 82 times greater in a terraced house than in a detached house). This pattern is probably explained by the tendency for few non-detached dwellings to be located in sparsely populated rural areas with no access to mains services.

Household age All variables are significant in this category at the $1 \%$ level. The baseline scenario is 'built before 1900', and all other variables are more likely to have mains connections. The strongest association with mains access is for properties built in the 1960s and 1970s.

\footnotetext{
${ }^{1}$ The full correlation matrix is available on request from the authors.
} 
Years at address The longer a household has been resident at a dwelling, the less likely it is to have either a water or sewage mains connection. Indeed, for every year a household has been resident at a dwelling the odds of having a sewage (water) mains connection falls by a factor of $0.02(0.01)$. Note that we have also controlled for the age of house and the age of the survey respondent.

Social status The baseline scenario for this category is 'high professional', and all other categories are less likely to have mains connections (though not always significantly so). Social status appears to be more pertinent to having a water mains connection than a sewage mains connection, as only three variables from six are significant even at the $10 \%$ level for the latter. However, it is not necessarily the case that those of a higher social status are more likely to have mains connections.

Household type The baseline scenario for this category is 'one adult under 65 years old'. All but one of the other variables have negative coefficients, indicating that they are less likely - than the baseline scenario-to have mains connections. However, only one variable is significant for both water and sewage mains connections, 'couple with children'; the odds of a household of this make-up having a mains sewage (water) connection is $30 \%(27 \%)$ less than the baseline scenario.

\subsection{Number of Appliances}

An ordered logit was run with outcomes being limited to whole numbers between zero and three, inclusive, indicating the total number of water-using appliances in each household. The reference category includes households with a head of household who is less than age 40 and is in the Professional social class; located in Dublin, with a dwelling that is owned outright, is a detached house and was built before 1900; and the family structure of the household is one person under 65. Table 4 shows the results from this regression, and the results are summarised below.

Similar to the interpretation of coefficients in the logit model, the figures under the column "coef." represent the effect that a one-unit change in that variable would have on the dependent variable. That is, for a given variable, the coefficient (say, X) implies that a one-unit change in that variable results in an X change in the dependent variable. In an ordered logit, confusion often arises because the dependent variable has a limited number of values, each represented by 'cut points' (see the last three rows in this table). In general, positive coefficients imply a higher probability that the household will be observed in a higher category (i.e. have more appliances), and negative coefficients imply a higher probability that the household will be observed in a lower category (i.e. have fewer appliances).

Exactly how many appliances one can expect a given household to have is less obvious from a cursory glance at the data. However, one can determine the probability that a household belongs above or below a certain cut point. For example, the probability of a household with a mains water connection with otherwise average characteristics having zero appliances (below _cut1) is the probability that $0.175+$ $u_{j} \leq 3.85$, or, or, equivalently, $\operatorname{Pr}\left(u_{j} \leq 3.68\right)$. Applying the logistic distribution $\frac{1}{\left(1+e^{3.68}\right)}$ we get a probability of 0.0247 or $2.47 \%$.

The direction and relative magnitude of variables' effects is probably of more immediate interest that their effects on the probabilities of having specific numbers 
Table 4 Regression results for total number of water-using appliances in home using an ordered logit; reference categories: age $<40$, locDublin, tenureOwn, socProf, dwellDetached, HAgePre1900, HH1under65

\begin{tabular}{|c|c|c|c|}
\hline Variable & Coef. & Odds ratio & Std. err. \\
\hline sewagetype & 0.175 & 1.19 & $0.0376^{\mathrm{a}}$ \\
\hline watertype & -0.0851 & 0.918 & $0.0309^{\mathrm{a}}$ \\
\hline yrshere & -0.00635 & 0.994 & $0.000861^{\mathrm{a}}$ \\
\hline Inhvalue & 0.588 & 1.8 & $0.0231^{\mathrm{a}}$ \\
\hline lnHHincome & 0.219 & 1.24 & $0.0210^{\mathrm{a}}$ \\
\hline HHsize & 0.0568 & 1.06 & $0.00964^{\mathrm{a}}$ \\
\hline age $<40$ & REF & & \\
\hline age40_64 & 0.0668 & 1.07 & $0.0341^{\mathrm{b}}$ \\
\hline age65plus & -0.199 & 0.82 & $0.0491^{\mathrm{a}}$ \\
\hline locDublin & REF & & \\
\hline locBMWurban & 0.0432 & 1.04 & 0.0443 \\
\hline locothurban & -0.0858 & 0.918 & $0.0362^{\mathrm{b}}$ \\
\hline locruralBMW & 0.110 & 1.12 & $0.0442^{\mathrm{b}}$ \\
\hline locothrural & 0.142 & 1.15 & $0.0427^{\mathrm{a}}$ \\
\hline tenureOwn & REF & & \\
\hline tenurePurch & 0.084 & 1.09 & $0.0266^{\mathrm{a}}$ \\
\hline tenureLocalA & -0.0896 & 0.914 & $0.0537^{\mathrm{c}}$ \\
\hline tenurePrRent & -0.912 & 0.402 & $0.0713^{\mathrm{a}}$ \\
\hline tenureVolOrg & -0.836 & 0.433 & $0.288^{\mathrm{a}}$ \\
\hline tenureRentFr & -0.480 & 0.619 & $0.141^{\mathrm{a}}$ \\
\hline socProf & REF & & \\
\hline socLowProf & -0.148 & 0.862 & $0.0409^{\mathrm{a}}$ \\
\hline socOthNonMan & -0.307 & 0.735 & $0.0418^{\mathrm{a}}$ \\
\hline socSkill & -0.392 & 0.676 & $0.0425^{\mathrm{a}}$ \\
\hline socSemiSkill & -0.492 & 0.611 & $0.0472^{\mathrm{a}}$ \\
\hline socUnskill & -0.552 & 0.576 & $0.0508^{\mathrm{a}}$ \\
\hline socUnknown & -0.361 & 0.697 & $0.043^{\mathrm{a}}$ \\
\hline dwellDetached & REF & & \\
\hline dwellSemiD & -0.306 & 0.736 & $0.0333^{\mathrm{a}}$ \\
\hline dwellTerrace & -0.443 & 0.642 & $0.0389^{\mathrm{a}}$ \\
\hline dwellPurpApt & -0.466 & 0.628 & $0.136^{\mathrm{a}}$ \\
\hline dwellHousApt & -0.82 & 0.441 & $0.203^{\mathrm{a}}$ \\
\hline dwellCaravan & -1.46 & 0.233 & $0.262^{\mathrm{a}}$ \\
\hline HAgePre1900 & REF & & \\
\hline HAge1900_40 & -0.127 & 0.881 & $0.0434^{\mathrm{a}}$ \\
\hline HAge1941_60 & -0.0069 & 0.993 & 0.0433 \\
\hline HAge1961_70 & 0.137 & 1.15 & $0.045^{\mathrm{a}}$ \\
\hline HAge1971_80 & 0.064 & 1.07 & 0.0404 \\
\hline HAge1981_90 & -0.0300 & 0.97 & 0.0452 \\
\hline HAge1991_96 & 0.0708 & 1.07 & 0.0546 \\
\hline HAgeAfter97 & 0.297 & 1.35 & $0.0591^{\mathrm{a}}$ \\
\hline HH1under65 & REF & & \\
\hline HH1over65 & 0.0943 & 1.1 & 0.0739 \\
\hline
\end{tabular}

of appliances. To facilitate this sort of comparison, Table 4 also includes an odds ratio for each variable. This represents the effect of a one unit change in a variable (e.g. from zero to one for a dummy variable) on the odds that a household will have an extra appliance. For example, an increase of one in household size implies 1.06 times 
Table 4 (continued)

\begin{tabular}{llll}
\hline Variable & Coef. & Odds ratio & Std. err. \\
\hline HHCoupleKids & 0.637 & 1.89 & $0.0643^{\mathrm{a}}$ \\
HHOthKids & 0.657 & 1.93 & $0.0763^{\mathrm{a}}$ \\
HHParAduKids & 0.547 & 1.73 & $0.0599^{\mathrm{a}}$ \\
HHOthAdUn65 & 0.403 & 1.5 & $0.0581^{\mathrm{a}}$ \\
HHOthAdOv65 & 0.514 & 1.67 & $0.0695^{\mathrm{a}}$ \\
/cut1 & 3.85 & & 0.302 \\
/cut2 & 7.53 & & 0.302 \\
/cut3 & 10 & & 0.304 \\
Number of obs. & 35,436 & & \\
LR $\chi^{2}(40)$ & 5,830 & & \\
Log likelihood & $-35,800$ & & \\
Pseudo $R^{2}$ & 0.0754 & & \\
\hline
\end{tabular}

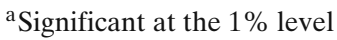

${ }^{\mathrm{b}}$ Significant at the $5 \%$ level

${ }^{\mathrm{c}}$ Significant at the $10 \%$ level

higher odds that a household will have four appliances rather than 1-3. Odds ratios are often used to illustrate relationships that are probabilistic (such as in discrete choice models) rather than marginal effects on quantities (where elasticities would be more common).

As shown in Table 4, nearly all of the variables used to predict households' numbers of appliances have a high level of significance. The following factors have a positive influence on owning more appliances:

House value In general, the more valuable a household's dwelling, the more appliances it tends to have. This is also the case for household income, where a doubling in income increases the odds ratio by $24 \%$.

Number of persons in a household Larger households, as expected, tend to own more appliances.

Social Status In general, the higher a household's social status, the more appliances it has.

House age Although not all of the variables are significant in this category, more recently built dwellings built since 1997; residing in a house from this period improves the odds of having another appliance by $35 \%$ compared to those in pre-1900 houses.

Household type Compared to the baseline, 'one person under 65', all other groups are likely to have more appliances, particularly households with children, the odds for whom of having an extra appliance are about $90 \%$ higher than the baseline.

Years at address The longer a household has been resident at a dwelling, the fewer appliances it tends to possess. For every decade a household is resident at a dwelling the odds of it having an additional appliance are diminished by about $6 \%$, if all other variables are kept the same. 
Dwelling type Compared to the baseline, 'detached house', all other dwelling types are less likely to have as many appliances, particularly-and not unexpectedlycaravans. Living in a caravan diminishes the odds of being in a higher category by $30 \%$.

Mains connection Although having a water mains connection appears to diminish the likelihood that a household will have more appliances, having a sewage connection would appear to increase this likelihood. This seems counter-intuitive, and the result may be affected by the correlation between these two variables (correlation $=$ 0.65). For example, it appears that having a sewage mains connection increases the odds of having one more appliance by $19 \%$, if all other variables are kept the same.

Respondent age Respondents in the '40-64 year old' group are likely to have more appliances than those in the baseline 'under forty' group, yet those in the 'sixty-five and older' group have fewer appliances than the reference group.

Location Not all variables in this category are significant, but living in a rural area increases the odds of having an extra appliance by $12-15 \%$ compared to living in Dublin.

Tenure type Compared to the baseline scenario of 'own outright', those who are purchasing their homes are more likely to have more water-using appliances (having this form of tenure improves the odds of having an extra appliance by $9 \%$ ). However, households of all other tenure types generally have fewer appliances, particularly private renters.

\section{Conclusions}

Developing optimal policies on management of water resources, investment in relevant infrastructure and the protection of the environment requires data on the current and likely future demand for water services. Partly because Ireland does not yet have widespread water metering or per unit charging for households, such data are very limited. However, household survey data can provide information about the relative importance of some drivers of water services demand; in particular household and area characteristics that affect the propensity to have mains water connections and to employ a range of water using appliances. In this paper we explore such relationships using regression analysis on a large cross-sectional survey. First, we investigate what factors are influential in determining whether a dwelling is connected to the public water and sewerage mains. Second, we examine what distinguishes households that have differing numbers of types of appliances. Using regression methods that allow for a discrete dependent variable (logit and ordered), independent variables related to both household and dwelling characteristics are included.

Our empirical results suggest that Ireland will have a rising share of mains water and sewerage connections in the future. Higher incomes, falling average household sizes, more expensive dwellings, dwelling types other than 'detached', younger dwellings, and urban location are all positively associated with having a mains connection; and all tend to be rising over time in Ireland. 
Our results concerning mains connections also have implications for the prevalence of water-using appliances, according to our second model. Having a mains sewerage connection is associated with $19 \%$ higher odds of having an additional appliance, while having a mains water connection is associated with $9 \%$ lower odds. Since these two connections often come together for a household, the net effect on appliance access of being connected to both mains is positive. Note that this effect does not necessarily imply causality in one direction (i.e. that getting a mains connection makes a household more likely to obtain appliances). Having more appliances could also lead to a preference for mains water services.

Not surprisingly, households with higher incomes tend to have access to significantly more water-using appliances. A positive association with the number of appliances also extends to dwelling value, number of persons in the household, owning rather than renting a residence, having children (or, to a lesser extent, multiple people) in the household, having a detached house, being located in a rural area and living in a dwelling built after 1997. We were unable to control for the internal size of the residence, but there seems to be a rough negative association between dwelling size and appliance ownership via the house type variable. Households living in house types that normally have smaller internal areas such as apartments and caravans have the strongest negative associations. Households headed by over 65 year olds, having lower social class status and those resident a long time at the same address also tend to have fewer appliances.

These findings fall short of the level of detail and predictive power that one might expect to achieve in a jurisdiction with metered water usage data. However, in the absence of such data, our results can be combined with demographic and macroeconomic projections of household characteristics to help policymakers identify likely developments in the appliance-driven component of domestic water demand.

Since household survey data tends to be available in most countries (it is required for other purposes such as setting price index baskets and measuring poverty), this approach may be of assistance in other places that do not employ domestic water metering.

In general, and in Ireland specifically, it will of course be of great benefit if metered domestic water use data can be collected in combined with data on household characteristics in the future. The design of the planned programme to introduce metering should take such informational benefits into account.

Acknowledgements We are grateful to two anonymous referees for helpful comments and to the Environmental Protection Agency for funding under the STRIVE programme.

Open Access This article is distributed under the terms of the Creative Commons Attribution Noncommercial License which permits any noncommercial use, distribution, and reproduction in any medium, provided the original author(s) and source are credited.

\section{References}

Aitken C, Duncan H, McMahon TA (1991) A cross-sectional regression analysis of residential water demand in Melbourne, Australia. Appl Geogr 11(2):157-165

Babel MS, Das Gupta A, Dhangana JR (2003) Modeling urban water demand in Bangkok City. In: Proceedings of the first international conference on hydrology and water resources in Asia and Pacific Region, 13-15 March, Kyoto, Japan 
Camp, Dresser and McKee (2004) Economic analysis of water use in Ireland. Final Report, Department of Environment, Heritage and Local Government, Dublin. Available at: http://www.wfdireland.ie

Dandy G, Nguyen T, Davies C (1997) Estimating residential water demand in the presence of free allowances. Land Econ 73(1):125-139

Dube E, van der Zwaag P (2003) Analysing water use patterns for demand management: the case of the City of Masvingo, Zimbabwe. Phys Chem Earth 28(20-27):805-815

European Commission (2007) Addressing the challenge of water scarcity and droughts in the European Union. Communication from The Commission to the European Parliament and the Council, COM (2007) 414 final

Haug P (2004) Decreasing population and rising costs of providing water and sewage treatment within cities: a case study. ERSA conference papers ersa04p353, European Regional Science Association

Hoehn JP, Krieger D (2000) An economic analysis of water and wastewater investments in Cairo, Egypt. Eval Rev 24(6):579-608

Inman D, Jeffrey P (2006) A review of residential water conservation tool performance and influences on implementation effectiveness. Urban Water Journal 3(3):127-143

Larson BA, Gnedenko ED (1999) Avoiding health risks from drinking water in Moscow: an empirical analysis. Environ Dev Econ 4:565-581

Lawlor J, McCarthy C, Scott S (2007) Investment in water infrastructure: findings from an economic analysis of a national programme. J Environ Plan Manag 50(1):41-63

Lenihan B (2009) Financial statement of the Minister for finance Mr Brian Lenihan, TD, 9 December. http://www.budget.gov.ie/Budgets/2010/Documents/FINAL\%20Speech.pdf

Malla PB, Gopalakrishnan C (1997) Residential water demand in a fast-growing metropolis: the case of Honolulu, Hawaii. Int J Water Resour Dev 13(1):35-51

McPhail AA (1994) Why don't households connect to the piped water system? Observations from Tunis, Tunisia. Land Econ 70(2):189-196

Scott S (1999) Water pricing: conceptual and theoretical issues. Paper presented to the conference 'Pricing water: economics, environment and society' organised by the European Commission DG XI and Instituto da Agua (Portugal), Sintra, 6-7 September

Scott S, Lawlor J (1994) Waste water services: charging industry the capital cost. ESRI Policy Research Series 22. ESRI, Dublin

Scott S, Lawlor J (1997) Environmental services. In: Barrett A, Lawlor J, Scott S (eds) The fiscal system and the polluter pays principle: a case study of Ireland. Ashgate, Aldershot

Scott S, Morgenroth E (2006) Water and waste water infrastructure. In: Morgenroth E, Fitz Gerald $\mathrm{J}$ (eds) Ex-ante evaluation of the investment priorities for the national development plan 20072013. ESRI, Dublin

Tol RSJ, Commins N, Crilly N, Lyons S, Morgenroth E (2009) Towards regional environmental accounts for Ireland. J Stat Soc Inq Soc Irel 38:105-142

Troy P, Holloway D (2004) The use of residential water consumption as an urban planning tool: a pilot study in Adelaide. J Environ Plan Manag 47(1):97-114

Vossler CA, Espey J, Shaw WD (1998) Trick or treat? An offer to obtain metered water. J Am Water Resour Assoc 34(5):1213-1220

Watson D, Williams J (2003) Irish national survey of housing quality. The Economic and Social Research Institute, Dublin

Wentz EA, Gober P (2007) Determinants of small-area water consumption for the City of Phoenix, Arizona. Water Resour Manage 21:1849-1863

Wooldridge JM (2002) Econometric analysis of cross-section and panel data. MIT, Cambridge 